\title{
A case of pulsating sternal and clavicular metastases of thyrofollicular carcinoma
}

\author{
Dhalapathy Sadacharan, ${ }^{1}$ Shriraam Mahadevan, ${ }^{2,3}$ Kirti Katherine Kabeer, ${ }^{4}$ \\ Gokulakrishnan Sundarraman ${ }^{4}$
}

\section{'Department of Endocrine} Surgery, Madras Medical College, Endocrine and Speciality clinic, Chennai, Tamil Nadu, India

${ }^{2}$ Endocrinology Department, Sri Ramachandra Medical College, Chennai, Tamil Nadu, India ${ }^{3}$ Endocrinology Department, Endocrine \& Speciality Clinic, Chennai, Tamil Nadu, India ${ }^{4}$ Department of Endocrine Surgery, Apollo Hospitals Chennai, Chennai, Tamil Nadu, India

\section{Correspondence to} Dr Shriraam Mahadevan, mshriraam@gmail.com

Accepted 15 March 2017

\section{DESCRIPTION}

Bony metastases are not infrequently encountered with follicular carcinoma of thyroid. Rarely, papillary thyroid carcinoma spreads to bones ${ }^{1}$; however, anterior chest wall (sternal and clavicular) involvement are rare. A 54-year-old man with long-standing ( $\sim 25$ years) multinodular goitre presented with recent-onset rapid enlargement of the sternoclavicular area beneath the goitre. On examination, the swelling was hard, warm and pulsatile and in addition showed engorged anterior chest wall veins (figure 1). He was clinically and biochemically euthyroid. Chest X-ray (figure 2) showed huge thyroid mass with sternal and clavicular erosion confirmed by CT (figure 3 ). Fine-needle aspiration cytology of the goitre and bony mass confirmed follicular carcinoma. $\mathrm{He}$ underwent total thyroidectomy with excision of the sternal and clavicular metastases and reconstruction of the chest wall defect with Marlex mesh. Following surgery, he underwent radioiodine therapy $(200 \mathrm{mCi})$ and the post-therapy scan showed multiple pulmonary macronodular spread

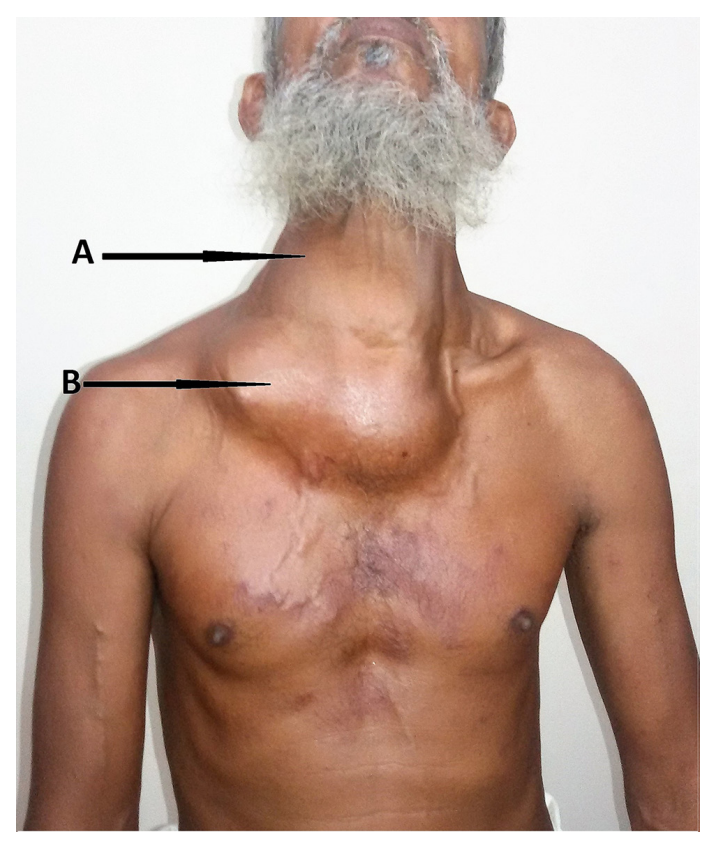

To cite: Sadacharan $D$, Mahadevan S, Kabeer KK, et al. BMJ Case Rep Published Online First: [please include Day Month Year]. doi:10.1136/bcr-2017220010

\section{CrossMark}

Figure 1 Shows the clinical picture with huge thyroid swelling (arrow A) with the bony lesion in continuity below (arrow B). Multiple prominent dilated veins are visible over the chest wall and upper arm due to the superior venacaval obstruction.

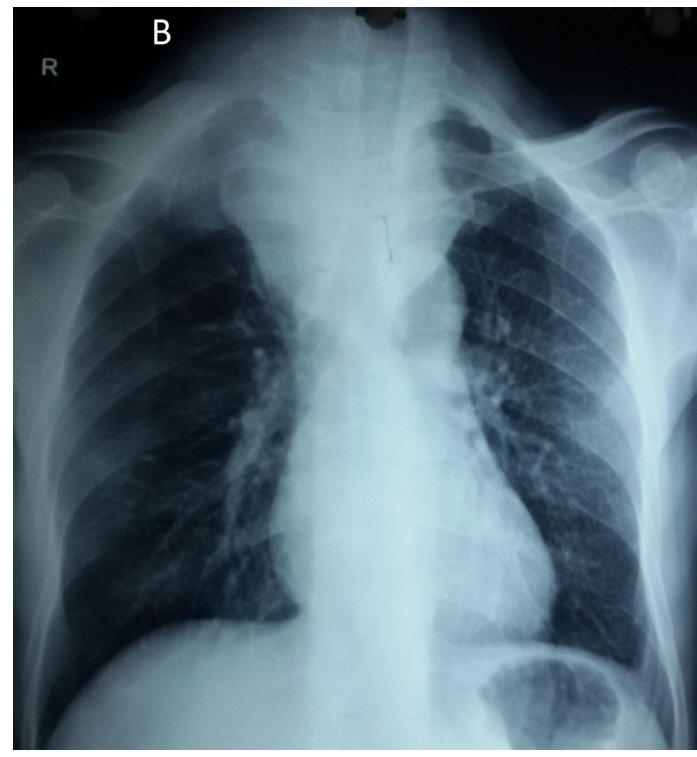

Figure 2 Skiagram of the chest, showing the trachea shifted to the left side and mediastinal widening seen because of the chest wall metastases.

with no residual iodine avid lesions in the sternum and clavicles. At 1-year follow-up, the patient was doing fairly well on suppressive therapy with thyroxine.

If not surgically excised, bone metastases of thyrofollicular carcinoma are difficult to manage as they respond poorly to radioiodine therapy. Inoperable bony secondaries especially if painful may to a reasonable extent be ameliorated by external radiotherapy. The reduction in tumour load by surgical removal of the large bone metastases in the index patient immensely helped better ablation of the pulmonary metastases with radioiodine. $^{2}$

Learning points

- Bony metastases are uncommon in thyroid cancers.

- Solitary bone metastases are amenable for surgery.

- Excision of these bone metastases improve radio iodine therapy and patient care. 


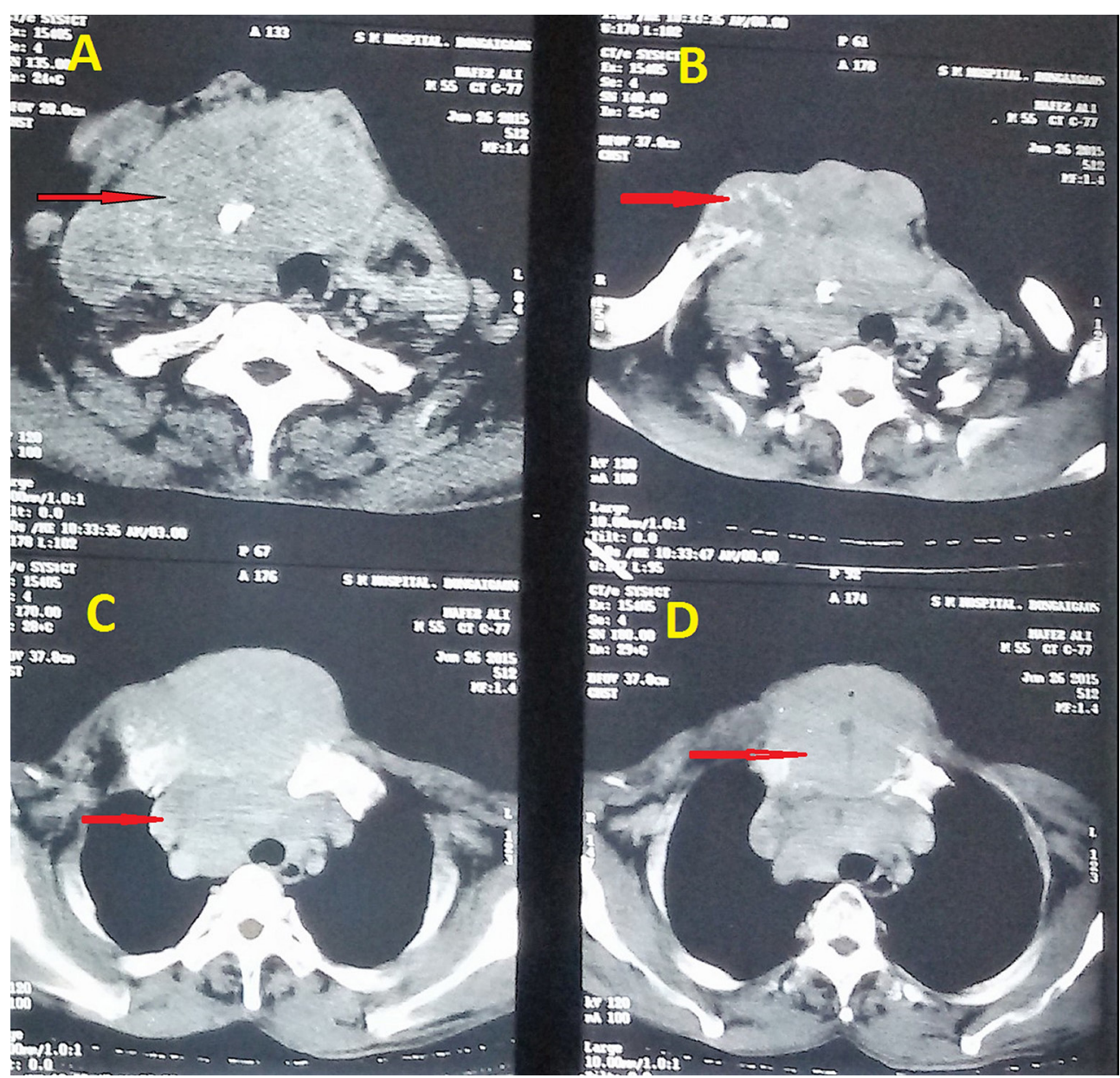

Figure 3 Contrast-enhanced CT, marked with arrows: (A) the vascular right thyroid lobe enlargement, (B) the destructed end of the right clavicle, (C) the retrosternal extension of the thyroid tumour and (D) the sternal destruction and expansion by the metastases.

Contributors DS and SM contributed in manuscript preparation. DS, KKK and GS contributed in patient management and manuscript preparation.

Competing interests None declared.

Patient consent Obtained

Provenance and peer review Not commissioned; externally peer reviewed.

(c) BMJ Publishing Group Ltd (unless otherwise stated in the text of the article) 2017. All rights reserved. No commercial use is permitted unless otherwise expressly granted.

\section{REFERENCES}

1 Spartalis E, Moris D, Tomos P. Sternal metastasis as first presentation of a well-differentiated papillary thyroid carcinoma. Surgery 2017;6060:30077-6.

2 Mishra A, Mishra SK, Agarwal A, et al. Surgical treatment of sternal metastases from thyroid carcinoma: report of two cases. Surg Today 2001;31:799-802.

Copyright 2017 BMJ Publishing Group. All rights reserved. For permission to reuse any of this content visit http://group.bmj.com/group/rights-licensing/permissions.

BMJ Case Report Fellows may re-use this article for personal use and teaching without any further permission.

Become a Fellow of BMJ Case Reports today and you can:

- Submit as many cases as you like

- Enjoy fast sympathetic peer review and rapid publication of accepted articles

- Access all the published articles

- Re-use any of the published material for personal use and teaching without further permission

For information on Institutional Fellowships contact consortiasales@bmjgroup.com

Visit casereports.bmj.com for more articles like this and to become a Fellow 